\title{
God's problem of multiple choice
}

\author{
Lloyd Strickland \\ Department of Religious Studies, Lancaster University, Lancaster, LA1 4YG
}

\begin{abstract}
A question that has been largely overlooked by philosophers of religion is how God would be able to effect a rational choice between two worlds of unsurpassable goodness. To answer this question, I draw a parallel with the paradigm cases of indifferent choice, including Buridan's ass, and argue that such cases can be satisfactorily resolved provided that the protagonists employ what Otto Neurath calls an 'auxiliary motive.' I supply rational grounds for the employment of such a motive, and then argue against the views of Leibniz and Nicholas Rescher to show that this solution would also work for God.
\end{abstract}




\section{A multiple-choice problem}

It has been urged by various thinkers that even if the notion of the best possible world is perfectly coherent, the term may not be applicable to merely one out of a presumed infinity of possible worlds. That is to say, the description 'is unsurpassed in terms of merit' may well have more than one referent from among the range of possible worlds that comprise God's choice. Richard Swinburne, John Mackie, Michael Banner, Joshua Hoffman and Gary Rosenkrantz all advocate the view that if there is a limit to the merit a world can have, it is likely that there will be more than one world exemplifying that level of merit. ${ }^{1}$ Even Kant, during his early optimistic phase, realised that if there was an unsurpassable world from among all the possibles, it need not be uniquely so:

there is a possible world, beyond which no better world can be thought. Admittedly, it does not, of course, follow from this that one among all the possible worlds must be the most perfect, for if two of more such possible worlds were equal in respect of perfection, then, although no world could be thought which was better than either of the two, neither of them would be the best, for they would both have the same degree of goodness. ${ }^{2}$

Kant was thus quick to realise that if there were two or more unsurpassable worlds, each equal in perfection to the other, then neither could properly be called the best. ${ }^{3}$ At first blush this might not seem like a particularly high price to pay, as presumably the optimist would just replace 'best' with 'unsurpassable' when describing the world God made. But the hypothesis that there are multiple unsurpassable worlds could potentially pose problems for the optimist beyond the inconvenience of not being able 
to describe God's creation as best. For optimists, and indeed most theists, hold that for God to act there must be an overriding reason for him to do so. ${ }^{4}$ And in this lies the nub of the difficulty of having more than one possible world of unsurpassable merit, for where two or more worlds recommend themselves to God equally there could be no overriding reason for him to choose one over the other(s). So a sort of divine paralysis is assumed, with God caught frozen between equally good alternatives and unable to make a choice between them.

The issue in question — how God could make a choice in this situation — is thus akin to that of Buridan's ass, the historical paradigm used to illustrate the difficulty of indifferent choice. Buridan's ass is usually conceived to be in a state of hunger and standing between two haystacks, either side of it and at an equal distance away. As it has no overriding reason to move towards one haystack rather than the other it is assumed that the ass must fail to choose and thus starve to death whilst still in a state of indecision. The same type of paradox has historically been presented in many different ways, e.g. a choice between two roads of equal length to one's destination (Buridan), a choice between two similarly appealing ladies of the court (Bayle), and more recently, a choice between two fresh dollar bills (Nicholas Rescher). Each example turns on precisely the same problem of making a choice without preference. How then best to solve it? We might suppose that Leibniz, as one of the few cardcarrying optimists in the history of philosophy, might have some useful words to say on the problem of choice without preference since it looms menacingly over all forms of optimism, including his own. But given the favour his philosophy accords to the principle of sufficient reason it is little surprise to find him affirming that in cases where a will is indifferent to the choices in front of it, it will not choose. He writes, 
Indifference is absolute when the will finds itself of the same mind in relation to each side, and is not inclined towards one more than the other... What point is there in fighting for these things which never exist? I do not think such indifference ever exists, or if it does exist, then as long as it remains no act will follow. ${ }^{5}$

And so, in the case of Buridan's ass, '[i]t is true that, if the case were possible, one must say that the ass would starve to death. ${ }^{6}$

As Leibniz does not exempt God from the principle of sufficient reason, it seems reasonable to suppose that if there were two or more unsurpassable worlds he would have God fail to choose through lack of preference. This is confirmed in his Theodicy, where he informs us that 'amongst an endless number of possible worlds there is a best of all, else would God not have determined to create any.' ${ }^{7}$ This remark is made in the context of there being an apex to the pyramidal series of possible worlds from which God makes his choice. Within this passage there is the deeper claim that there must be a single best world in order that God be moved to create anything.

A modern-day optimist considering how best to respond to the problem of indifferent choice will thus derive no comfort from Leibniz. And so long as the paradox of indifferent choice is treated as a strictly logical problem there can be no escape from the conclusion that the agent will fail to act. However, if the paradox is to be considered purely as a logical problem, then it is arguable that Buridan's ass ought not to be considered as the paradigm example; a more appropriate illustration of indifferent choice would involve replacing Buridan's ass with a robot, which is programmed to approach haystacks. Assuming the robot is able to measure distances to a very high degree of accuracy, and thus recognise haystack A and haystack B to be 
equidistant from it, then it is reasonable to suppose, ceteris paribus, that it will not approach either haystack. The robot follows only logic and it is its unswerving adherence to logic that prevents it from moving towards one haystack or the other. Yet we feel certain that no rational being would suffer the same fate-whether it be Buridan's ass, a man, or God. So the question to be asked is: what is the difference between this example and the case of Buridan's ass, or the person offered a choice between two fresh dollar bills, or God faced with two unsurpassable worlds? At first glance there seems to be nothing particularly different, as in each case the same two options are available to the chooser as they are to our robot, viz. choose one alternative or the other.

\section{Two alternatives, three choices}

But of course it is to oversimplify the matter to say that Buridan's ass, for instance, is faced with just the two choices of haystack 1 and haystack 2, as there is a third option open to it as well, viz. starving to death whilst standing between the two. This is clearly not an option open to the robot as it does not, properly speaking, have the power to choose in the same way that a creature does.

By extending the range of choices to three, I believe we have discovered the germ of a satisfactory solution to the puzzle of choice without preference. Before we develop this point further it is worth tackling an obvious objection to this extension of choices, the objection being that starving to death is not really a choice at all but the inevitable result of indecision over the two genuine choices available (eat haystack 1 or eat haystack 2). If this is correct, then the ass doesn't actually make a choice to starve, it just starves because of its failure to choose between haystacks. 
Such an objection would, I think, be misguided, for the ass clearly has two possible paths to starvation - choose it as an option in itself, or fail to choose between the two haystacks on offer. We may call starvation a genuine choice as the ass always has the option of starving to death if it so chooses, no matter how many haystacks surround it. If there was just the one haystack available to eat, it still has the choice of whether or not to eat it, and the same is true if there were ten haystacks in the vicinity, or a hundred, or any number you care to choose. It would be odd indeed to say that the choice to starve exists at every moment and in every scenario except for when it finds there are only haystacks (or other sources of food) equidistant from it. Starving is thus a genuine choice. ${ }^{8}$

Now assuming the ass to be normal, i.e. that it is not bent on self-extinction, we can say with some confidence that it will reject the starvation option. It is, after all, the worst of the three choices open to it, and no rational being would freely choose what it considers to be worst option available. But once the starvation option is rejected, this seems to take us right back where we started, for now it is faced with the same two choices (haystack 1 or haystack 2) with which it has been presented throughout antiquity, and it is no closer to being able to decide between them. One might therefore wonder if it might just end up starving to death anyway, since it still lacks the means to make a choice.

And indeed, if the ass fails to make a choice between haystacks it will starve to death. But if the ass were now to starve to death, by inaction rather than positive choice, then the crucial point to bear in mind is that it will have allowed to happen the very thing that it has decisively rejected. That this would not be rational should be clear enough, and no reasoning being would permit it to happen if it can possibly help it. For it would be the height of irrationality to allow the very state of affairs to come 
about that it has already rejected, which of course was the worst of the three possible outcomes.

The point I am trying to make here is this: once we introduce a third choice (deliberately starve) the problem shifts from being a strictly logical paradox to a matter of rationality. We move from asking 'what is the logical way to break the deadlock of indifferent choice?' to asking 'what is the most rational option available in these circumstances?' This is without question a subtle shift in emphasis but an important one, and will require a little explanation.

Paradoxes constructed along the lines of Buridan's ass have traditionally been construed as straightforward logical problems. They involve the protagonist being placed in a very simple dilemma — select one of the alternatives, or fail to make a selection. The paradox assumes that in order to choose one of the alternatives the protagonist must have a sufficient (overriding) reason to do so. Being a free agent, this reason can only be found in the protagonist's preference for one alternative over the other. Now in order for there to be such a preference there must either be a logically significant difference between the two alternatives, or the protagonist must at least perceive there to be such a difference. But of course in the state of affairs described by the paradox neither is the case. And as there is no logically significant difference between the two alternatives, and as the protagonist correctly perceives this, there will obviously be no sufficient (overriding) reason for preferring one alternative to the other. ${ }^{9}$ Consequently the only logically acceptable horn of the dilemma is to fail to make a selection. The failure to choose is not just the logical outcome of the paradox, however, but the only rational outcome too. For rationalityquite literally 'reasonableness' - requires that an agent have some reason for acting. And since it is assumed that this reason must be found in the agent's preference, his 
lack of preference means that there can be no reason to act. So both logic and rationality require that the agent fail to choose. Thus the possible outcomes of the theoretical paradox of indifferent choice are as follows:

(1) Choose alternative A (irrational, as there is no sufficient reason to do so over alternative B)

(2) Choose alternative B (irrational, as there is no sufficient reason to do so over alternative A)

(3) Make no choice (rational, as there is no logically significant difference between $\mathrm{A}$ and $\mathrm{B}$ )

However it would be a mistake to assume that this analysis applies also to real-life forms of the puzzle, for in all real-life cases the puzzle can only arise as a direct result of a preceding choice made by the agent. Which is to say, in order to get to the point where the agent is actively faced with indifferent alternatives, he must have rejected the option not to bother with the alternatives in the first place. He could have opted not to engage the alternatives on the grounds that he was uninterested in what they had to offer. But if he is interested, and decides to engage with the alternatives, then the whole complexion of the puzzle changes, and the possible outcomes are now as follows:

(1) Choose alternative A (irrational, as there is no sufficient reason to do so over alternative B)

(2) Choose alternative B (irrational, as there is no sufficient reason to do so over alternative A) 
(3) Make no choice (irrational, since this leads to the agent bringing about (or causing to endure) a state of affairs that he has already rejected)

Thus option (3) changes from being the only rational outcome in the theoretical form of the puzzle, to being yet another irrational outcome in the practical form of the puzzle. Of course there is still no logically significant difference between A and B, and hence no sufficient reason for a preference, but that is no longer grounds for adopting the third option. In fact quite the opposite, as the agent now has sufficient reason not to adopt (3). Logically, of course, the agent must end up doing one of the three, as they exhaust his options and he cannot choose or fail to choose one of the alternatives. But the principle of sufficient reason demands that (1), (2) and (3) all be rejected, as there is no sufficient reason for an agent to opt for any of them. And where the principle of sufficient reason breaks down and leads to logical absurdity, as it does here, the agent can only have recourse to its less stringent counterpart, the principle of insufficient reason. ${ }^{10}$ Such a principle will allow the agent to select (1), (2) or (3) via a reason that would be considered unacceptable (insufficient) in normal circumstances, but is nevertheless perfectly acceptable in the highly unusual situation we are here discussing.

So what are insufficient reasons? In almost every state of affairs we can conceive, we find that there will be competing reasons for action. These reasons typically vary in quality, so that there is, for instance, a reason for a man diagnosed with liver disease to cut down on his alcohol intake (as it will lead to a slowing of the disease's progress), and a reason for him to become a teetotaller (as this will arrest the progress of the disease). Now although he may recognise that he has a reason to cut down on his alcohol intake, he also recognises that he has a better reason to become a 
teetotaller. So the former reason is deemed insufficient for action, as a better reason is available. Insufficient reasons are thus grounds for action, but grounds that are ordinarily not considered good enough to prompt an agent to do that action because they are bettered by other reasons. In making this observation it is not my intention to stray from the widely accepted view that agents routinely act on the best reason available. Rather, I am attempting to show that usually there are other, lesser reasons on which action could be based if the agent is unable to act on the best reason, or if no best reason is available. In such circumstances these lesser reasons can be brought into play by the principle of insufficient reason to ensure that logical absurdity does not arise as a result of there being no sufficient reason to either do A or not do A.

Returning, then, to the main argument, we can be sure that the principle of insufficient reason will not lead an agent to option (3) as that option has already been rejected. So it must lead the agent to opt for (1) or (2). It can only do this by ignoring the fact that there is no logically significant difference between A and B, and thus allowing the agent to make a choice between them without requiring that such a difference be found. It is important to note that this does not mean that the agent can turn his back on rationality altogether and select one of the alternatives without any reason at all. There must still be a reason, it just need not answer to the description of 'sufficient'.

Thus once an agent has decided to engage in an indifferent choice situation, what he requires is some way of breaking the deadlock that doesn't simply involve making an irrational reason-less choice between whatever alternatives are on offer (which is presumably impossible anyway). In other words, what he requires is a means of selection that cannot be traced back to his will, thus absolving him of any charge of irrationality, but is nevertheless connected to him in that he accepts whatever selection 
is made on his behalf. Thus the only choice he will make in the situation is to let an external means of selection decide which alternative is to be favoured over the other. At this stage all we can say is that such a means of selection will be external to the agent, and thus external to his will.

Clearly, anything that fits the bill will not be as rational as making a choice based solely on sufficient, overriding reasons, which is how agents usually act. But in the circumstances it will be the most rational way to proceed, as the other ways are (a) to choose an alternative without any reasons at all, or (b) to fail to choose and thus allow a state of affairs to arise that one has already rejected. Since neither of those are in any way rational it must be that any method of effecting a solution that involves at least some modicum of rationality (or rather, is at least not wholly irrational) will be the most rational thing to adopt in the circumstances. So what is the method that allows an agent to break out of an indifferent choice situation with his rationality intact?

\section{$\underline{\text { Auxiliary motives }}$}

To break the deadlock in such circumstances Otto Neurath suggests that one should employ what he calls an 'auxiliary motive. ${ }^{11}$ Neurath conceives this as a procedure that in no way alters the circumstances responsible for the deadlock, but will nevertheless assist in bringing the matter to a swift and successful close (thus functioning as 'an aid to the vacillating, so to speak'). Neurath suggests that 'The auxiliary motive appears in its purest form as a drawing of lots,' and elsewhere implies that tossing a coin is also adequate for the purposes of a swift resolution. ${ }^{12} \mathrm{~A}$ very similar suggestion is also made by Nicholas Rescher-apparently independently —at the end of his paper surveying the history of Buridan's ass and the associated family of paradoxes. Rescher also urges that the deadlocked chooser should 
implement a selection policy that is ultimately underpinned by randomness, for 'Random selection is the only reasonable procedure for making choices in the face of symmetric preference.' ${ }^{13}$

I am inclined to agree, as a random selection procedure meets the requirements I laid down earlier, namely that the actual selection must be made by something external to the agent in order to protect the agent from the charge that he acted irrationally, i.e. without reason. To be sure, the result of a random process doesn't afford the most rational reason for decision-making - it is not the sort of thing on which a rational being would ordinarily base his decisions after all—but in the circumstances we are considering, where the agent is deadlocked by two equally attractive alternatives, it is the most rational way of resolving the matter. Provided that the agent has got himself into the position where a choice must be made on pain of irrationality, because he has rejected the option not to engage in the indifferent choice situation, an auxiliary motive in the form of a random selection policy is the only way he can make a choice while leaving his rationality intact.

Rescher sees things somewhat differently, however, and attempts to demonstrate the reasonableness of a random selection procedure via another route. He does this using the example of a man who has the choice between two ostensibly identical dates (an example drawn from Ghazali). There are, says Rescher, three courses of action open to such a man: 
procedure which favors one over the other

(3) To select one of the dates at random

One date

It is mandatory that some one of the trio be adopted, and impossible to adopt more than one: the procedures are mutually exclusive and exhaustive. ${ }^{14}$

Rescher observes that while options (2) and (3) lead to the same reward, (2) does so irrationally while (3) does not. Thus (3) is to be preferred. But by construing the matter in terms of potential rewards, Rescher is vulnerable to any number of 'Hobson's choice'-type counterexamples that do not involve considerations of reward at all. For example, suppose a person is cornered by a psychopath and offered the choice of being shot through the left temple or right temple. To keep this example in line with that of Buridan's ass, make the further assumption that the person does not want to be shot. On Rescher's analysis, option (2) results in death, as does option (3), so opting for either of these alternatives would not lead to any obvious reward. This leaves option (1), to select neither alternative for lack of a preference. This certainly qualifies as the option involving the greatest reward, since in indifferent choice situations it is assumed that either alternative is brought about only if the chooser selects it, and if the chooser fails to make a choice then the status quo is maintained. So in this example the psychopath will only shoot the chooser if he opts for either (2) or (3), and for however long the chooser is paralysed by indecision he will remain alive. But this does not mean that Rescher's option (1) is in any way rational in this case as it involves the chooser actually struggling to make a choice between equally bad alternatives (since being paralysed by indecision implies that the chooser does want to be able to make a choice). In fact the only rational option in this case is the 
one Rescher does not permit, viz. deliberately choosing not to answer the psychopath on the grounds that the chooser just does not want to engage in the indifferent choice situation at all.

The same applies if God's creative options are exhausted by two equally dreadful worlds. Being good and wise God would simply choose not to create at all in this situation, and consequently would not be drawn into the knotty process of how best to make a choice between two worlds he does not want anyway.

Rescher's attempt to ground the rationality of a choice made via a random selection procedure thus makes the unwarranted assumption that indifferent choice situations always involve potential rewards. But the bare bones paradox of indifferent choice does not discriminate between cases where the alternatives are equally good and cases where they are equally bad, and so the move to recommend a random selection procedure cannot unequivocally hinge on considerations of rewards as they are not always present. Therefore Rescher's option (3) cannot be said to be rational per se, but only becomes rational once the chooser has elected to engage in the situation at hand.

There is a further weakness in Rescher's analysis that is worth noting, for it attempts to isolate the indifferent choice scenario from the real world, by assuming that the agent involved must make a choice between alternatives or be paralysed by deadlock, and overlooks the fact that the agent need not engage the situation at all if he does not want to. The analysis I have presented allows for the fact that the agent can simply ignore the alternatives on offer if he so wishes, which goes a long way towards putting indifferent choice situations in a real-life context. 


\section{Three kinds of random choice}

How, then, does the agent in an indifferent choice situation go about making a random choice? One way would be for him to choose whichever alternative he happens upon first, a solution proposed by the Aristotelian commentator Simplicius ('Whatever happens first we choose first'). ${ }^{15}$ Rescher describes such an approach as 'wholly acceptable' (on the grounds that we may consider the order in which the options are presented to be random), and for many indifferent choice scenarios it surely is. But while opting for the first-perceived alternative may well be an adequate approach for men and asses, it is unlikely to be a policy suitable for God, who is generally considered to be outside time. Hence when God surveys all possible worlds this is not done one after another, but all together. So it would be inappropriate to say that God happens upon one of the hypothetical unsurpassable worlds before the other(s). And since God considers all worlds from a timeless perspective it is clearly not open to him to select one on the basis that it is presented to him before any others of equal merit.

Another possible way of making a random choice would be what we might call mere will. Championed by Bayle, this option involves the will simply making an arbitrary choice on the basis that man 'is master is his own house, and...he does not depend upon objects. ${ }^{16}$ Rescher appears in places to endorse this line, claiming that random decision-making is an ability possessed by the human mind, 'since men are capable of making arbitrary selections, with respect to which they can be adequately certain in their own mind that the choice was made haphazardly, and without any "reasons" whatsoever., ${ }^{17}$ There seem to me to be two ways of construing the notion of an arbitrary choice here. The first is to say that when agents make choices in ways considered to be arbitrary, they are in fact acting on reasons of which they themselves 
are barely aware, if they are aware of them at all. A person acting under hypnotic suggestion or a subconscious motive could be said to be acting on such reasons. Now if an arbitrary choice is to be understood in this way, as a choice made on the basis of reasons which are barely (if at all) perceptible to the agent involved, then this is entirely satisfactory concept. Arbitrary choice would simply be a species of rational choice - choices based on sufficient reasons. So to call a choice arbitrary would be to say that there is a sufficient reason for the choice, though the agent is not fully cognisant of it. But of course arbitrary choice so conceived is not going to be employable in properly-constructed indifferent choice situations, as it requires that there be logically significant differences between the alternatives on offer, or at least that the agent perceives there to be so. Yet in a true indifferent choice scenario these differences or perceived differences are of course totally absent. Ergo, this notion of arbitrary choice is utterly unequipped to solve the problem of choice without preference.

The second way of construing the notion of an arbitrary choice is to take it at face value and say that it simply involves choosing without any reasons at all. If this is what is meant by the expression 'arbitrary choice' then I am not convinced that the expression is intelligible. If we leave this complaint aside, and assume that agents do have the ability to make arbitrary choices in this sense, then we can say without fear of contradiction that any choice they would make using such an ability would not be in any way rational. For if the will could be moved without any reason(s) whatsoever, then it would be moved irrationally. ${ }^{18}$ So flattering oneself that one is 'master in his own house' and choosing arbitrarily would break the deadlock of an indifferent choice situation, but it would not conclude the matter in the way that we want, i.e. in a manner not entirely irrational. Thus it is not an appropriate option for God, even in the 
event that his will has the capacity to be moved without reasons (which seems unlikely given that God is generally considered to be the most rational of beings, which would hardly be an appropriate epithet for a being capable of acting without any reason at all). ${ }^{19}$

A third possible method of random choice has been put forward by Rescher. Developing a line first found in Bayle, he proposes that making use of a randomising device or a random selection procedure would be a reasonable way to break the deadlock in cases where one or more options are of equally good merit. This certainly does seem promising, for the random element is here external to the agent, and thus excuses his will from having to make a random choice. Rescher attempts to garner support for the reasonableness of the proposal by noting that leaving a 'choice without preference' matter in the hands of a randomising device or random selection policy 'has acquired the status of customary, official mode of resolution. ${ }^{20}$ But once we swing the discussion back around to the issue at hand, that of God trying to choose which world to create when faced with two or more of equal merit, we are informed by Rescher that a problem emerges and that resorting to a random choice is entirely inappropriate for God. Why? Because, being omniscient, he will always foreknow the outcome of any random process. ${ }^{21}$ But this strikes me as highly doubtful. The hallmark of random event or mechanism is that the outcome is unknowable in advance. That is, what it is for something to be genuinely random is for it to be entirely unpredictable. Consequently many of the procedures and mechanisms we would call random (e.g. dice, roulette wheels, coin tosses) are only random to us, in that their outcomes are generally unknowable to us. ${ }^{22}$ But there seems to be no incoherence in the idea of a process or mechanism that is unknowable or unpredictable by its very nature. Such a process/mechanism would be truly random, in 
that once started it is impossible for any being to know what the outcome of it will be until it happens (so it would be the sort of process that just has no truth value for however long the process happens to last) ${ }^{23}$ No doubt some theists would argue that such an idea is incoherent, because God's omniscience rules out there being any process or thing that is unknowable by its own nature. Such reasoning would be unconvincing, I think, because the notion of a process whose outcome is unknowable even to God seems to have a vaguely analogous parallel with free beings—beings that by their very nature are uncontrollable, even by God. Now it seems to me that if there are things that do not fall under the scope of God's power, i.e. free beings that he cannot control, then there might also be things, not necessarily the same things, that do not fall under the scope of his knowledge, e.g. things or processes which are just inherently unknowable. So just as God's omnipotence is not circumscribed by his creation of things over which he has no subsequent control, so his omniscience is not circumscribed by his instigation of a process or mechanism whose outcome it is logically impossible for him to foreknow. Thus there does not seem to be any contradiction in the notion of a process or mechanism that is by its very nature unknowable, that is, a process or mechanism that is truly random, and if that is so then it seems God could have recourse to it in order to break the deadlock of an indifferent choice.

\section{The problem of association}

But while the notion of a truly random process seems coherent in itself, it is possible to object to its use in indifferent choice situations. This objection can be traced back at least as far as Leibniz, who levels it in the following way: suppose we were to decide an indifferent choice situation by flipping a coin, for example. To do 
that, he observes, 'There would have to be a reason to attribute heads to one [option] and tails to the other rather than the contrary. ${ }^{24}$ But of course there is no good reason to make such an attribution, and since the process of attribution is itself an indifferent choice we very quickly find ourselves heading towards an infinite regress. The same problem is going to occur with other procedures too, such as drawing straws, throwing dice etc.

Rescher is aware of this problem-though he seems not to be aware that it is to be found in Leibniz-and suggests that it can be resolved by what he calls 'convenience.' This is where, for example, the chooser accepts the first option presented (or the last, or the penultimate, etc.) on the basis that it is the most convenient thing to do. The chooser can do this, argues Rescher, on the grounds that 'the order-of-mention (or indication) can be taken, by the defining hypothesis of the problem, to be a random ordering. ${ }^{25}$ In circumstances where the alternatives can be considered to be randomly ordered, the use of a further random selection policy is strictly not necessary at all, he argues, and one can just choose whichever alternative is the most convenient (however defined). I shall not consider this suggestion further, being content to mention in passing that it appears to involve an indifferent choice of its own, for the decision whether to nominate the first-presented option or lastpresented option as the most convenient must be made before the options are presented (since choosing the first-presented or last-presented must form part of a consistent policy, as Rescher notes, and not be liable to amendment every time an indifferent choice situation arises). ${ }^{26}$ In any case, whatever merit Rescher's proposal has, it is clear again that it would not be suitable for God's purposes since possible worlds cannot be said to be in any kind of ordering whatsoever (as they are not 
surveyed in either time or space). So there would seem to be no method of convenient selection open to God.

This ought not to be considered a particularly great setback, however. For it needs to be noted that Leibniz's problem of association only applies to particular selection methods, such as tossing a coin, throwing dice or drawing straws, as in each of these methods an association clearly has to be made between the instruments (or parts of instruments) used and the choice-alternatives that they are supposed to represent. But the problem of association does not arise with every type of selection procedure that we would consider to be random. For instance, if I were presented with a choice between two dates I could put them in a lottery ball selection machine and let that select one for me. No association is required with this method as the selection is direct rather than indirect, as it is with coins, straws and dice. Likewise one can imagine a selection device that just randomly points in a particular direction. Again, if one's random selection policy involved using such a device then one would not be troubled with the matter of associating the choice-alternatives to the means of selection, as no association would be required. Since there are means of selection that do not require any form of association we can therefore suppose that whatever selection policy God happens to favour, it would not be one that requires association.

This is not to say, of course, that God would use some kind of cosmic lottery machine. None of the means of selection we have mentioned thus far-coins, straws, dice, lottery machines etc.- - are plausible candidates for a divine random selection procedure as, notwithstanding the fact that none of them are truly random in the sense of their having outcomes that are logically unknowable in advance, they are all very much rooted in the spatio-temporal world, whereas God is not. It is God's extramundane-ness that makes it extremely difficult to figure out the sort of random 
procedure he could use, as it would obviously be some procedure utterly unlike any we employ. ${ }^{27}$ For one thing, all of our random procedures, which as I have mentioned are not really random at all, absolutely speaking, are physical in nature. God, however, is not restricted to selection procedures involving physical objects. I remain silent as to whether an appropriate divine random selection procedure would be physical or non-physical in nature, as for our purposes I do not think it matters much either way (since God, after all, could avail himself of any random selection procedure, physical or otherwise). Accordingly, all references to a 'random procedure' or 'random mechanism' should henceforth not be taken narrowly to refer to a procedure or a mechanism that is physical, but rather to some kind of process or method, however instituted, of making a random selection, where this process or method is not simply a random movement of the will (which, as I have noted, is irrational, and thus not in accordance with God's supreme rationality).

Now the important point to glean from all this is as follows: the problem of association only arises with some selection procedures, and those in which it does arise are (a) random to us, but not random per se, and (b) physical in nature. On this basis I cannot see that we have any good reason to suppose that the problem of association would arise for a selection procedure that (a) is genuinely random, and (b) may or may not be physical in nature. Moreover, there seems to be no obvious contradiction inherent in the notion of a truly random selection procedure that does not suffer from the problem of association, and on that basis I submit that such a thing is possible. In which case God would be able to make use of it should he find that there is more than one possible world of unsurpassable goodness. 


\section{A further problem of multiple choice}

However even if we allow that there is such a thing as a truly random selection procedure that does not suffer from the aforementioned problem of association, the problem of how God can choose one world from several equally good alternatives does not necessarily end there. For prima facie it seems possible that there will be more than one such procedure available to God, and if there are many such procedures then it is possible, and even quite likely, that some or even all of them will be equally good but not bettered by any other. If we suppose for the sake of argument that there are 10 equally good (and unsurpassable) procedures that God could employ, it is clear that God is faced with yet another indifferent choice scenario, for he needs to choose one random procedure out of 10 in order to whittle down his choice of equally good worlds. But he has no reason to select any of the random procedures over the others, since all are ex hypothesi equally good. So if we allow that there might be more than one random selection procedure open to God, then not only is he once again faced with an indifferent choice (this time between random selection procedures), but this time he has no means by which he can rationally break the deadlock, because his method of breaking the deadlock in indifferent choice situations, i.e. employing a random selection procedure, is in fact the cause of this particular indifferent choice problem.

As stated, the problem seems insuperable. But in fact it is not, for there is a significant difference between having to make a choice between equally good worlds and equally good random selection procedures, and it is this: in the case of worlds, God can only choose one, but in the case of random selection procedures there is nothing to stop him choosing them all. A little explanation will make this clear. Logically, of course, God can only choose one world (i.e. universe), for it is literally 
impossible for him to create more than one. There is thus a logical restriction on the number of worlds he can create. A similar restriction is present in some forms of the indifferent choice paradox too, e.g. Buridan's ass can only choose to go in one direction at a time, and is artificially built in to other forms of the paradox, e.g. a person offered two dollar bills is only permitted to take one of them. But no such restriction applies to random selection procedures since it is logically possible to select them all. So if God is faced with 10 different-but-equally-good random selection procedures to choose from, there is nothing to prevent him from selecting them all in the way that there is something preventing him from selecting all equally best worlds. And the decision to select all available random procedures can hardly be said to be an irrational act either, unlike the remainder of God's options, which are to choose none of the procedures, or just one of them (for which he would of course have no reason at all). So if there are 10 procedures, God can simply select and run them all, and then pool the results. If one of the equally best worlds is selected more often than any other, then that is the world he creates, and if the combined results of all the random procedures do not favour any one world over the others then God can simply run all of them again until a clear winner does emerge.

It seems not unreasonable, then, that in the event of his being faced with two or more unsurpassable worlds God could have recourse to one or more random selection procedures in order to choose between them. To the unpersuaded, I shall note only this - if for some reason it is not possible for God to arbitrarily select for creation one from two or more equally meritorious unsurpassable possible worlds, then presumably it was not required of him anyway. We can be confident of this because we know that there is a world. Therefore if the optimist is right that God will choose a world unsurpassable by any others, then clearly one of two possible scenarios obtained: (1) 
God found only one unsurpassable world among all those possible, and actualised it on the grounds that it was the best, or (2) There were two or more unsurpassable worlds, and God was able to choose between them.

A third scenario would no doubt be urged by many- that God did not make an unsurpassable world at all, on the grounds that the very concept of an unsurpassable world is incoherent. ${ }^{28}$ To that I would respond: if there is no such thing as a world unsurpassable in merit, then the problem of how God can make a rational choice of world is even more thorny than in the scenario we have been discussing. For if God is faced with an unbounded infinity of possible worlds, with no limit to how meritorious a world can be, then for whichever world he chooses there is always another that is better, and clearly he will have no overriding reason to make any of them. And the need to uncover a rational selection procedure is very pressing indeed if one rejects the notion of an unsurpassable world, as is evidenced by the efforts of Robert Adams, Francis \& Daniel Howard-Snyder and Richard Swinburne, who have all attempted, unsuccessfully in my view, to develop one. ${ }^{29}$ Where there is no best possible world, only an infinite series of them ascending in merit, one struggles to imagine what possible reason God could have to settle for any of the choices on offer, knowing full well that many superior worlds are available. At least the optimist appears to be on firmer ground when it comes to explaining how God made his choice.

Thus we may say that if God were faced with two possible worlds of equal merit and unsurpassed by no other possible worlds, he would choose one of them for creation via a random selection procedure. This is because, contra Leibniz, choosing one this way, either one, would be the rational thing to do. ${ }^{30}$ 
NOTES 
${ }^{1}$ Richard Swinburne The Existence of God (Oxford: Clarendon Press, 1991), 113-114. John L. Mackie The Miracle of Theism (Oxford: Oxford University Press, 1982), 173. Michael Banner The Justification of Science and the Rationality of Religious Belief (Oxford: Clarendon Press, 1990), 157. Joshua Hoffman \& Gary S. Rosenkrantz The Divine Attributes (Oxford: Blackwell, 2002), 158-159.

${ }^{2}$ Immanuel Kant 'An attempt at some reflections on optimism' in Theoretical Philosophy 1755-1770, trans \& ed: David Walford \& Ralf Meerbote (Cambridge: Cambridge University Press, 1992) 72 [AK 2.30].

${ }^{3}$ Kant attempted to sidestep the problem by arguing that what made possible worlds different from each other was their degree of perfection, so there just could not be two different worlds exemplifying the same degree of perfection. Kant, like many in the $18^{\text {th }}$ century, equated the degree of perfection of a thing with its degree of reality, and it is on this identification that he pins his belief that no two things can possess the same degree of perfection. 'Different things can never have the same degree of reality,' he wrote, for if things differ at all 'then they differ in virtue of something which is present in the one thing and not in the other.' That is, things 'differ from each other only in virtue of the negations, the absences and limits attaching to one of them.' Consequently 'two different worlds can never have the same degree of reality' as there must be something positive in one that is lacking in the other for them to be different at all. Despite his protestations, this does not seem to rule out the possibility that worlds could differ in detail not connected to the degree of reality they contain. For example, two possible worlds could be identical save for the location of one pebble, or be identical aside from the fact everything in one world is $1 \%$ bigger than in the other. Kant rides roughshod over the suggestion that worlds could differ in quality but not reality, simply remarking that this is not so. Consequently we may consider the question of whether two worlds can possess the same degree of perfection very much begged. See Kant 'An attempt at some reflections on optimism', 72-73 [AK 2.31].

${ }^{4}$ I should point out that my use of the masculine pronoun and its cognates to refer to God is not intended in any way to be gender-exclusive.

${ }^{5}$ Gottfried Wilhelm Leibniz Textes Inédits, ed: Gaston Grua, 2 vols with successive pagination (Paris: Presses Universitaires de France, 1948), 385. Translations from this volume are my own.

${ }^{6}$ Gottfried Wilhelm Leibniz Theodicy, trans: E. M. Huggard (Chicago: Open Court, 1990) 150. It is worth pointing out that Leibniz did not believe such a case to be possible. Instead, he argued that the problem of indifferent choice is a fiction and only occurs inside the heads of philosophers, never in the real world. For the case of Buridan's ass 'deals in the impossible, unless it be that God bring the thing about expressly. For the universe cannot be halved by a plane drawn through the middle of the ass, which is cut vertically through its length, so that all is equal and alike on both sides... [T] $]$ he case of a perfect equipoise between two courses is impossible.' Leibniz Theodicy, 150, cf. 310, 312. Even if he is right here, and that is by no means certain, such a response does nothing to address the theoretical problem of indifferent choice. 
${ }^{7}$ Leibniz Theodicy, 372.

${ }^{8}$ One could instead say that the ass has the option to just stand still, or to walk off somewhere and ignore the haystacks, but since these ultimately boil down to the same thing — starvation through a failure to eat - I have elected to bundle them all under the heading of 'choosing to starve.'

${ }^{9}$ I note in passing that most forms of the indifferent choice paradox also specify that there are no internal biases present in the agent, to rule out the possibility that he may opt for one alternative or another simply because he is left- or righthanded (a bias which may well make him more inclined to go in one direction over another).

${ }^{10}$ The name may be familiar to anyone versed in Mathematics and Physics, as a principle of insufficient reason appears in the work of Laplace and Bernoulli. However their concept of insufficient reason concerns probable outcomes, i.e. that if several outcomes of a process are possible, and it cannot be predicted which will occur, then all possible outcomes should be considered to be equally probable. It will become clear as my argument unfolds that I do not conceive the principle of insufficient reason this way, but rather as a backup principle for action in cases where the principle of sufficient reason does not or cannot apply.

${ }^{11}$ Otto Neurath 'The Lost Wanderers of Descartes and the Auxiliary Motive' in Philosophical Papers (Dordrecht: D. Reidel Publishing Company, 1983) 4. As befits a member of the Vienna Circle, Neurath was principally concerned with indifferent choice situations in science, where two competing theories were of equal probability.

${ }^{12}$ Neurath 'The Lost Wanderers of Descartes and the Auxiliary Motive', 4. For the coin example see 9.

${ }^{13}$ Nicholas Rescher 'Choice without preference' in Essays in Philosophical Analysis (Pittsburgh: University of Pittsburgh Press, 1969), 150.

${ }^{14}$ Rescher 'Choice without preference', 149.

${ }^{15}$ Quoted in Rescher 'Choice without preference', 117.

${ }^{16}$ Bayle's words, quoted in Leibniz Theodicy, 311.

${ }^{17}$ Rescher 'Choice without preference', 149.

${ }^{18}$ This is so because, by definition, a rational act is one done for a reason.

${ }^{19}$ This is overlooked by Joshua Hoffman \& Gary S. Rosenkrantz, who suppose that it would be rational for God to freely choose one from many unsurpassable worlds without having a reason to do so. See Hoffman and Rosekrantz The Divine Attributes, 175-176.

${ }^{20}$ Rescher 'Choice without preference', 150-151.

${ }^{21}$ Rescher 'Choice without preference', 156. The same point is made also by Stephen Grover 'This world, 'Adams worlds', and the best of all possible worlds', Religious Studies 39 (2003), 149, albeit in a slightly different context. ${ }^{22}$ I say 'generally unknowable' rather than just 'unknowable' because there have been instances where the outcome of a supposedly random process has been foreknown. The example that springs to mind is a news story from the UK, March 
2004 , in which a group of gamblers used a laser scanner and computer to predict the outcome of roulette in a London casino. The device was sufficiently sophisticated to advise them of the winning number in time for them to place their bets, and as a result they netted $£ 1.3 \mathrm{~m}$.

${ }^{23}$ Some theists would argue that such inscrutability is involved in the case of free beings, as a free decision has no truth value whatsoever until the decision is made. But this is not a widely held position.

${ }^{24}$ Leibniz, Textes Inédits, 488.

${ }^{25}$ Rescher 'Choice without preference', 147.

26 'It is important to note that the matter of a policy of choice is very important in this context. When I make a choice among symmetrically characterized alternatives, I can defend it, reasonably, by saying, "I choose the first mentioned (or the like) alternative, because I always choose the first mentioned (etc.) in these cases." But I cannot (reasonably) defend the choice by saying "I chose the first mentioned alternative because this seemed to me to be the thing to do in this case, though heaven knows what I would do another time."' Rescher 'Choice without preference', 147.

${ }^{27}$ An intriguing suggestion made by one of the Religious Studies referees is that of 'disjunctive creation', which would work like this: if God cannot choose between equally good possible worlds A and B he need only decree 'Let either A or B become actual', and because God's decrees must necessarily come to pass, one or other of A or B will somehow get actualised as a result. Assuming that God could not have foreknown which of A or B would be actualised, then the process qualifies as random under my definition of 'random'. Consequently, if disjunctive creation is actually an option for God, then it satisfies my requirement for a random selection process because (a) it will lead to the random creation of one or other of two equally good worlds, (b) the random choice cannot be traced back to God's will, which of course did not actually choose between A and B. My only reservation with this notion of disjunctive creation is that it is not clear how the selection between A and B comes to be made. Think of it as a three step process: the first step is God's disjunctive decree, and the third step is the actualisation of one or other of A or B. Between these two steps lies a second step, in which the selection between A or B takes place, but who or what does the selecting is a mystery. We know that God does not make the selection himself, and prior to creation there is presumably nothing and no one else in existence aside from God. How, then, does the selection between A or B come to be made? Although I shall leave it to the reader to decide if disjunctive creation can be made to work, I would like to thank the Religious Studies referee for bringing the idea to my attention.

${ }^{28}$ I argue against this claim in my paper 'Determining the best of all possible worlds', Journal of Value Inquiry, forthcoming. Atheists would of course argue for a fourth scenario that involves the world having a non-divine source, if indeed it is even allowed to have a source at all. But since the foregoing discussion takes place within a theistic framework, and thus assumes God to exist, all possible non-divine origins of the world are outside the scope of this paper. 
${ }^{29}$ Robert Adams 'Must God Create the Best?’, Philosophical Review, 81 (1972), 317-332. D. Howard-Snyder \& F. Howard-Snyder, F. 'How an Unsurpassable Being Can Create a Surpassable World', Faith and Philosophy, 11 (1994), 260-268. I note in passing that the Howard-Snyders attempt to defend the view that it would be rational for God to choose randomly if faced with an infinity of surpassable worlds. Richard Swinburne argues for this too:

Given that for every possible world, there is a better one, there is no world such that it is over all better that God should make that world than that he should make any other world... [Nevertheless, God] surely has reason to use some process of random selection or some arbitrary feature of a world to determine which to create... unlike Buridan's ass, he may make an arbitrary selection, and that will have been the rational thing to do. (Swinburne, The Existence of God, 115.)

What Swinburne fails to see here is that Buridan's ass has good reason to accept the outcome of a random selection procedure, as it will lead to an unsurpassable choice. But if God is faced with an infinite series of surpassable worlds then he will not have good reason to accept the outcome of any random selection procedure he may use, as there will always exist an even better reason for him to choose another world, randomly or otherwise, that is even better, and so on.

${ }^{30}$ I would like to thank Chakravarthi Ram-Prasad, Vernon Pratt, Patrick Sherry and two anonymous Religious Studies referees for helpful comments on an earlier draft of this paper. 